\title{
Resistance of Selected Saprobic and Zoopathogenic Fungi to Cycloheximide
}

\author{
By D. H. GRIFFIN AND S. B. SULLIA* \\ Department of Environmental and Forest Biology, State University of New York, \\ College of Environmental Science and Forestry, Syracuse, New York 13210, U.S.A. \\ AND I. F. SALKIN \\ Division of Laboratories and Research, New York State Department of Health, \\ Albany, New York 12201, U.S.A.
}

(Received 9 August 1977)

\begin{abstract}
Spore germination was used as an assay to measure the sensitivities of selected fungi (Achlya bisexualis, Cladosporium sp., Trichophyton mentagrophytes and Microsporum gypseum) to cycloheximide and to determine their abilities to adapt to the drug. Two patterns of response were noted. The saprobes, A. bisexualis and Cladosporium sp., demonstrated acquired resistance. Spores from hyphae previously exposed to cycloheximide either germinated in the presence of concentrations of the drug that completely inhibited spores from unexposed hyphae (Achlya), or germinated with a shorter lag and to a greater extent in the presence of the antibiotic than did spores from unexposed hyphae (Cladosporium). Hyphae of Achlya adapted at concentrations of cycloheximide in which spores did not germinate and hyphae of Cladosporium adapted more rapidly than spores. Achlya adapted to only $12 \mu \mathrm{M}$-cycloheximide whereas Cladosporium acquired resistance to 18 mu-cycloheximide. These fungi lost this acquired resistance after a single transfer to media lacking cycloheximide. The zoopathogens, T. mentagrophytes and $M$. gypseum, had a contrasting response, indicating constitutive resistance. Conidia from unexposed hyphae showed 90 to $100 \%$ germination on media containing up to $18 \mathrm{~mm}$-cycloheximide; prior exposure to the drug did not affect their response.
\end{abstract}

\section{INTRODUCTION}

Cycloheximide, an antibiotic produced by several strains of Streptomyces griseus (Krainsky) Waksman and Henrici (Ford \& Leach, 1948), inhibits the development of many eukaryotic organisms. Whiffen $(1948,1950)$ noted considerable variation in the sensitivity of fungi to the drug, but zoopathogens consistently grew at higher concentrations of antibiotic than saprobes and phytopathogens. This response led to the widespread use of cycloheximide in selective isolation and diagnostic media (Georg, Ajello \& Gordon, 1951; Taplin, Zaias \& Blank, 1969; Tsao, 1970). However, characterization of a fungus as either sensitive or resistant may be misleading, for response to cycloheximide depends upon a number of factors, particularly antibiotic concentration, duration of exposure and ability of the strain to acquire resistance (McDonough et al., 1960; Grover \& Moore, 1961; Gundersen \& Wadstein, 1962; Salkin \& Hurd, 1972; Salkin, 1975).

Methods of assessing sensitivities of fungi to cycloheximide have varied from simple observations of growth/no growth (Whiffen, 1948, 1950) and visual estimations of develop-

* Present address: Department of Botany, University of Bangalore, Bangalore, India. 
Table 1. Sources of cultures studied

\begin{tabular}{|c|c|c|c|}
\hline Organism & Perfect stage & Strain(s) & Source* \\
\hline $\begin{array}{l}\text { Saprobes } \\
\text { Achlya bisexualis } \\
\text { Cladosporium sp. }\end{array}$ & Achlya bisexualis & $\begin{array}{l}65-1 \\
242 \mathrm{~B}\end{array}$ & $\begin{array}{l}\text { D. H. Griffin } \\
\text { Laboratories for Mycology }\end{array}$ \\
\hline $\begin{array}{l}\text { Zoopathogens } \\
\text { Trichophyton mentagrophytes } \\
\text { Microsporum gypseum }\end{array}$ & $\begin{array}{l}\text { Arthroderma benhamiae } \\
\text { Nannizzia gypsea } \\
\text { Nannizzia incurvata } \\
\text { Not determined }\end{array}$ & $\begin{array}{l}354,362 \mathrm{~B}, 360 \mathrm{~A} \\
270 \mathrm{~B}, 270 \mathrm{~F}, 271 \mathrm{~L} \\
271,271 \mathrm{z}, 271 \mathrm{~J} \\
\text { R87 (ATCC } 28249)\end{array}$ & $\begin{array}{l}\text { Laboratories for Mycology } \\
\text { Laboratories for Mycology } \\
\text { Laboratories for Mycology } \\
\text { J. J. Stock }\end{array}$ \\
\hline
\end{tabular}

* Prof. D. H. Griffin, Department of Environmental and Forest Biology, State University of New York, Syracuse, New York 13210; Laboratories for Mycology, Division of Laboratories and Research, New York State Department of Health, Albany, New York 12201; Prof. J. J. Stock, University of British Columbia, Vancouver, British Columbia.

ment in six graded categories (McDonough et al., 1960) to measurements of the radial extension of colonies (Salkin \& Hurd, 1972).

We have determined percentage spore germination to compare the abilities of selected saprobic and zoopathogenic fungi to adapt to cycloheximide.

\section{METHODS}

Stock cultures. Sources of the cultures studied are given in Table 1. Stock cultures of Achlya bisexualis were maintained on slants of glutamate defined medium (Griffin, Timberlake \& Cheney, 1974) under paraffin oil; those of the other fungi were maintained on half-strength Sabouraud dextrose agar (Difco) supplemented with Difco Bacto-agar to $2 \%(\mathrm{w} / \mathrm{v})$. All stock cultures were incubated at $10^{\circ} \mathrm{C}$.

Preparation of spore suspensions. Encysted zoospores of $A$. bisexualis were obtained by a modification of the technique of Griffin \& Breuker (1969), in which $40 \mathrm{ml}$ glucose/casein hydrolysate broth medium (CAA; Griffin et al., 1974) was inoculated with $10^{5}$ spores and incubated at $28{ }^{\circ} \mathrm{C}$ on a New Brunswick rotary shaker operating at $100 \mathrm{rev} \cdot \mathrm{min}^{-1}$ for $24 \mathrm{~h}$. The resulting mycelium was harvested on a sterile glass Millipore filter holder and washed with sporulation medium $\left(0.25 \mathrm{mM}-\mathrm{KCl}\right.$ and $0.25 \mathrm{mM}-\mathrm{CaCl}_{2}$ in glass-distilled water $)$ using gentle suction. It was then suspended in $500 \mathrm{ml}$ sporulation medium in a 1 litre Florence flask and incubated overnight at $28^{\circ} \mathrm{C}$ on a reciprocal shaker with a $5 \mathrm{~cm}$ throw at 60 oscillations $\mathrm{min}^{-1}$. The suspension was then gravity filtered through a sterile Kimwipe (Kimberly-Clark) to separate the spores from the parent mycelium.

Cladosporium conidia, Trichophyton microconidia and Microsporum macroconidia were obtained by scraping the surface of 7-d-old cultures on Difco Cantino PYG agar with a wire loop and suspending the adherent fungus in a small volume of sterile distilled water. It was not necessary to separate the selected spore type from the other fungal elements.

Spore concentrations were determined with a Neubauer-Levy Ultra Plane haemocytometer (C. A. Hausser, Philadelphia, Pennsylvania, U.S.A.), and the suspension volumes for each strain of fungus were adjusted to give the following spore inocula: Achlya bisexualis, $3.5 \times 10^{4}$ encysted spores; Cladosporium sp., $1 \times 10^{5}$ conidia; Microsporum gypseum, $7 \times 10^{3}$ macroconidia; Trichophyton metagrophytes, $4 \times 10^{5}$ microconidia. These inocula, in 50 to $100 \mu 1$ water, were streaked evenly over the surface of Difco Cantino PYG agar and incubated at $28^{\circ} \mathrm{C}$ (all four species) and $37^{\circ} \mathrm{C}$ (Microsporum and Trichophyton).

Effect of cycloheximide on germination. Cycloheximide (Upjohn Co.) was sterilized by Millipore filtration $(0.45 \mu \mathrm{m}$ porosity) and added aseptically to cooled molten agar before pouring. The concentrations tested were in 10-fold increments from 0.012 to $12 \mu \mathrm{M}$ with Achlya, $1.8 \mu \mathrm{M}$ to $18 \mathrm{~mm}$ with Cladosporium and 1.8 and $18 \mathrm{~mm}$ with Microsporum and Trichophyton.

The standard error of the mean (s.E.M.) for the germination of Achlya spores (Table 2) was determined by counting 10 samples of 20 spores in fields selected at random using a compound microscope at $100 \times$ magnification. For the experiments showing the time course of germination, 100 spores were counted for each data point in fields selected at random using a compound microscope at $100 \times$ magnification for Achlya and Microsporum and at $240 \times$ magnification for Cladosporium and Trichophyton.

Measurement of acquired resistance to cycloheximide. Spores or hyphae formed on mycelium grown in the absence of cycloheximide are described as 'unexposed', while those spores and inocula produced from mycelium grown in media containing cycloheximide are described as 'exposed'. Exposed Achlya spores 
were produced with cycloheximide incorporated into both the medium for growth of mycelium and the sporulation medium at the concentrations given in Table 2. Concentrations of cycloheximide incorporated into PYG media to produce exposed Cladosporium conidia were $180 \mu \mathrm{M}, 1.8 \mathrm{~mm}$ and $18 \mathrm{~mm}$. Only the data for conidia exposed to $180 \mu \mathrm{M}$-cycloheximide are shown as the others gave substantially identical results.

The experiment presented in Fig. 1 $(b)$ was designed to ascertain how long it took for Achlya mycelium to acquire resistance to $12 \mu \mathrm{M}$-cycloheximide. CAA medium $(50 \mathrm{ml})$ inoculated with 3000 spores $\mathrm{ml}^{-1}$ was dispensed aseptically into sterile $250 \mathrm{ml}$ Erlenmeyer flasks and incubated on a New Brunswick rotary shaker $\left(120 \mathrm{rev} . \mathrm{min}^{-1}\right)$ at $28^{\circ} \mathrm{C}$. Cycloheximide $(12 \mu \mathrm{M})$ was added to some of the flasks $14 \mathrm{~h}$ after inoculation, the remainder served as untreated controls. The cultures from duplicates of control and treated flasks were harvested at the times indicated and dry weights were determined as described by Griffin et al. (1974).

The experiment presented in Fig. 1(c) was designed to ascertain when, in the course of germination of Achlya spores, resistance to $12 \mu \mathrm{M}$-cycloheximide was acquired. Cultures in CAA medium were prepared and incubated as described above and $12 \mu \mathrm{M}$-cycloheximide was added to triplicate flasks at the times indicated in Fig. 1 $(c)$. Incubation was then continued until $72 \mathrm{~h}$ when the cultures were harvested and their dry weights determined.

Effect of cycloheximide on growth rates. Cladosporium 242B mycelial macerate was prepared by first growing the organism on plates of modified Sabouraud dextrose agar [MSDA; $2 \%(\mathrm{w} / \mathrm{v}$ ) dextrose, $1 \%$ (w/v) Difco Neopeptone and $2 \%(w / v)$ agar] for $14 \mathrm{~d}$ at $27^{\circ} \mathrm{C}$. Four mm diameter plugs were then removed from the periphery of the culture with a stainless-steel cork borer, transferred to $50 \mathrm{ml}$ modified Sabouraud dextrose (MSD) broth in $125 \mathrm{ml}$ Erlenmeyer flasks, and incubated at $27^{\circ} \mathrm{C}$ in a Labline Environ shaker at $170 \mathrm{rev} . \mathrm{min}^{-1}$ for $14 \mathrm{~d}$. The mycelium/agar suspensions from two flasks were then aseptically suctionfiltered through a specially prepared $5 \mathrm{~cm}$ square stainless-steel wire basket held within a porcelain Buchner funnel. The suspension was washed twice with sterile saline, resuspended in $80 \mathrm{ml}$ MSD broth in a 1 litre monomel Waring blender cup, and homogenized for $25 \mathrm{~s}$ at high speed. The resulting brei was inoculated at $1 \mathrm{ml}$ per $50 \mathrm{ml}$ MSD in $125 \mathrm{ml}$ flasks and incubated as described above for $7 \mathrm{~d}$. This process, with incubation for $7 \mathrm{~d}$, was repeated twice to dilute out the remaining agar. Inocula for the growth experiments, prepared by this washing-blending procedure from 7-d-old macerate cultures descended from this initial process, amounted to 7 to $14 \mathrm{mg}$ dry wt per flask. Dry weights were determined as described by Griffin et al. (1974).

The growth curves for Achlya were determined as previously described (Griffin et al., 1974); cultures were incubated on a New Brunswick rotary shaker $\left(120 \mathrm{rev} \cdot \mathrm{min}^{-1}\right.$ at $\left.28^{\circ} \mathrm{C}\right)$ using $50 \mathrm{ml} \mathrm{CAA}$ per $250 \mathrm{ml}$ Erlenmeyer flask. Cultures from triplicate flasks were harvested at 45 to 90 min intervals and five mean data points were obtained during exponential-phase growth for each curve. To determine the growth curves for Cladosporium, cultures were incubated in a Labline Environ rotary shaker $\left(170 \mathrm{rev} . \mathrm{min}^{-1}\right.$ at $\left.27^{\circ} \mathrm{C}\right)$ using $50 \mathrm{ml}$ MSD broth per $125 \mathrm{ml}$ Erlenmeyer flask. Duplicate cultures were harvested at $12 \mathrm{~h}$ intervals and five mean data points were obtained during exponential-phase growth for each curve.

The specific growth rates $(\alpha)$ were determined by the least squares method and the statistical analysis of these data was according to Miller \& Freund (1965). The equation for $\alpha$ used in these calculations was:

$$
\ln \left(M_{2} / M_{1}\right)=\alpha\left(t_{2}-t_{1}\right)
$$

where $M_{1}, M_{2}$ are the dry weights at times $t_{1}, t_{2}$. Lag phases (see Results) were determined by calculating the time on the log growth lines described by equation (1) when the dry weight $M_{1}$ equalled the dry weight of the inoculum as measured at the time of inoculation.

\section{RESULTS}

\section{Achlya bisexualis}

Cycloheximide at 0.012 and $0.12 \mu \mathrm{M}$ had no effect on germination whereas $1 \cdot 2 \mu \mathrm{M}$ cycloheximide delayed the germination of unexposed spores of Achlya and $12 \mu \mathrm{M}$-cycloheximide caused total inhibition (Fig. 1a). Germination of unexposed spores on $12 \mu \mathrm{M}$-cycloheximide did not occur even after $21 \mathrm{~d}$ incubation. In contrast, unexposed hyphae grew, after a $45 \mathrm{~h}$ delay, in the presence of $12 \mu \mathrm{M}$-cycloheximide added $14 \mathrm{~h}$ after inoculation (Fig. $1 b$ ). The specific growth rates $(\alpha)$ of hyphae were $0.40 \mathrm{~h}^{-1}$ (s.E.M. $=0.058$ ) in the presence and $0.59 \mathrm{~h}^{-1}$ (s.E.M. $=0.053$ ) in the absence of the drug. The shift from sensitive spores to adaptable hyphae correlated with the appearance of germ tubes, which occurred $5 \mathrm{~h}$ after inoculation. Little growth was obtained when cycloheximide was added to the 

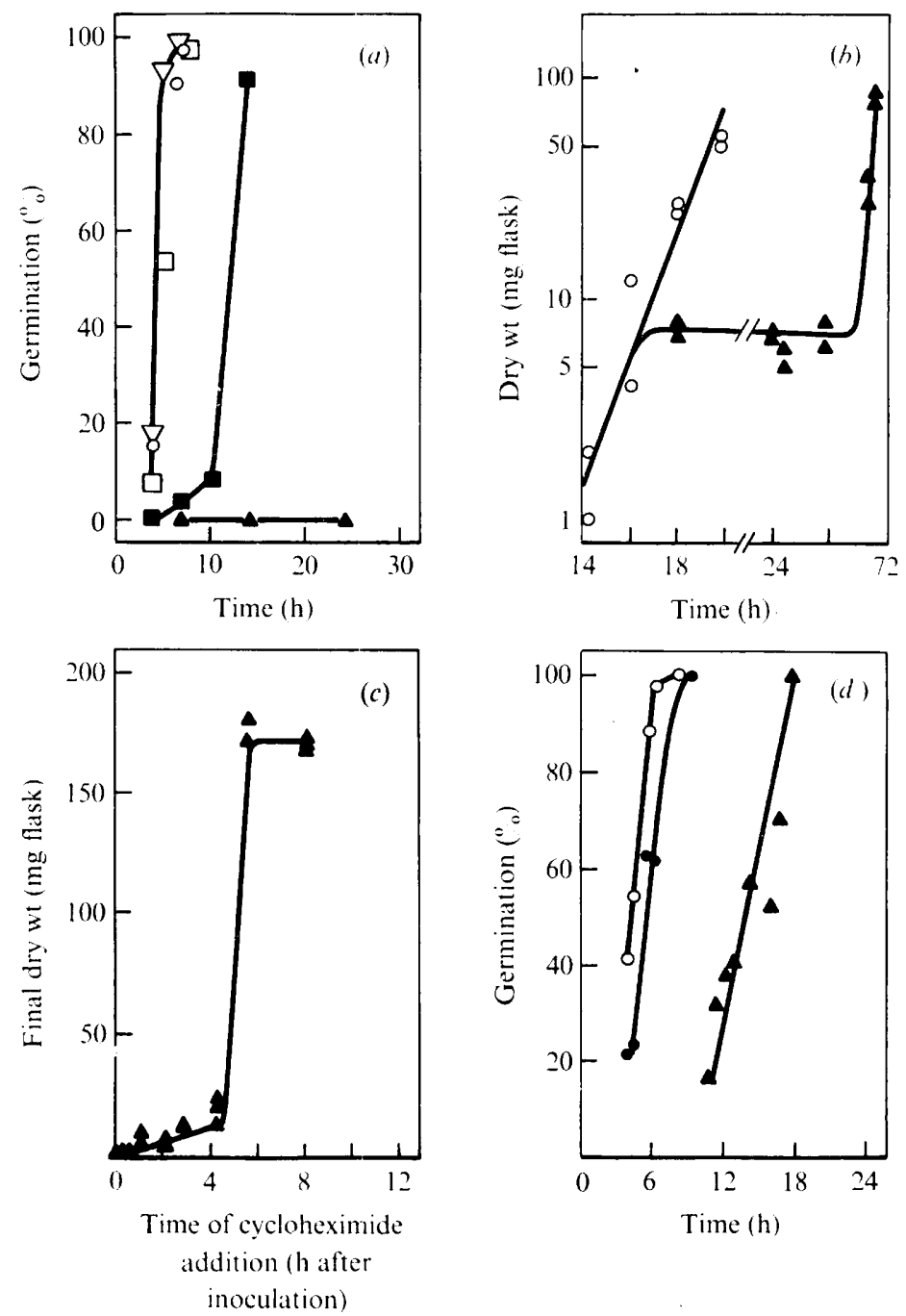

Fig. 1. Response of Achlya bisexualis to cycloheximide. (a) Percentage germination of unexposed spores in the presence of cycloheximide at $(\mu \mathrm{M}): \nabla, 0.012 ; \square, 0 \cdot 12 ; \mathbf{\square}, 1 \cdot 2 ; \Delta, 12 ; \bigcirc$, control (no cycloheximide added). (b) Development of unexposed hyphae in the presence of $12 \mu \mathrm{M}$-cycloheximide added $14 \mathrm{~h}$ after inoculation $(\Delta)$. Note the change in time scale after $20 \mathrm{~h}$. $\bigcirc$, Control (no cycloheximide added). (c) Growth of unexposed spores in the presence of $12 \mu \mathrm{M}$-cycloheximide added at different times after inoculation. (d) Percentage germination of exposed spores in the presence of $12 \mu \mathrm{M}$-cycloheximide $(\boldsymbol{\Lambda})$ or in its absence $(O)$, and of unexposed spores in the absence of cycloheximide $(\bullet)$. Unexposed spores did not germinate in the presence of $12 \mu \mathrm{M}$-cycloheximide even after $21 \mathrm{~d}$ incubation.

germination medium up to $4.5 \mathrm{~h}$ after inoculation; maximum growth was obtained when the drug was added $5.75 \mathrm{~h}$ after inoculation and later (Fig. $1 \mathrm{c}$ ).

No sporulation was observed when unexposed hyphae were transferred to sporulation medium containing $12 \mu \mathrm{M}$-cycloheximide. However, normal sporulation occurred when hyphae grown in the presence of $12 \mu \mathrm{M}$-cycloheximide were transferred to sporulation medium also containing $12 \mu \mathrm{M}$-cycloheximide. Spores derived from the latter germinated, after an $8 \mathrm{~h}$ delay, in medium containing $12 \mu \mathrm{M}$-cycloheximide (Fig. $1 d$ ) but spores from unexposed hyphae did not germinate even after $21 \mathrm{~d}$ incubation on this medum.

Germination of spores exposed to 0.012 to $1 \cdot 2 \mu \mathrm{M}$-cycloheximide was greater than that of 
Table 2. Germination of Achlya spores exposed to cycloheximide

Germination was scored $6.5 \mathrm{~h}$ after inoculation on PYG medium.

Results are expressed as percentage germination \pm S.E.M.

Cycloheximide in growth and sporulation media $(\mu \mathrm{M})$

0 0.012

$0 \cdot 12$

$1 \cdot 2$
Cycloheximide in germination medium $(\mu \mathrm{M})$

\begin{tabular}{|c|c|c|c|c|}
\hline 0 & 0.012 & $0 \cdot 12$ & $1 \cdot 2$ & $12^{*}$ \\
\hline $97 \cdot 5( \pm 3 \cdot 5)$ & $98 \cdot 5( \pm 2 \cdot 4)$ & $98 \cdot 5( \pm 2 \cdot 4)$ & $4 \cdot 0( \pm 2 \cdot 1)$ & $0.0( \pm 0.0)$ \\
\hline $99 \cdot 0( \pm 2 \cdot 1)$ & $98 \cdot 5( \pm 2.4)$ & $98 \cdot 5( \pm 2 \cdot 4)$ & $45 \cdot 0( \pm 13 \cdot 3)$ & $0.0( \pm 0.0)$ \\
\hline $99 \cdot 5( \pm 1.6)$ & $98 \cdot 0( \pm 2 \cdot 6)$ & $99 \cdot 5( \pm 1.6)$ & $91 \cdot 0( \pm 7 \cdot 4)$ & $0.0( \pm 0.0)$ \\
\hline $96 \cdot 5( \pm 4 \cdot 1)$ & $98 \cdot 0( \pm 2 \cdot 6)$ & $95.0( \pm 6.2)$ & $91 \cdot 0( \pm 7 \cdot 4)$ & $89 \cdot 5( \pm 7 \cdot 8)$ \\
\hline
\end{tabular}

* Germination scored $20 \mathrm{~h}$ after inoculation on PYG medium.

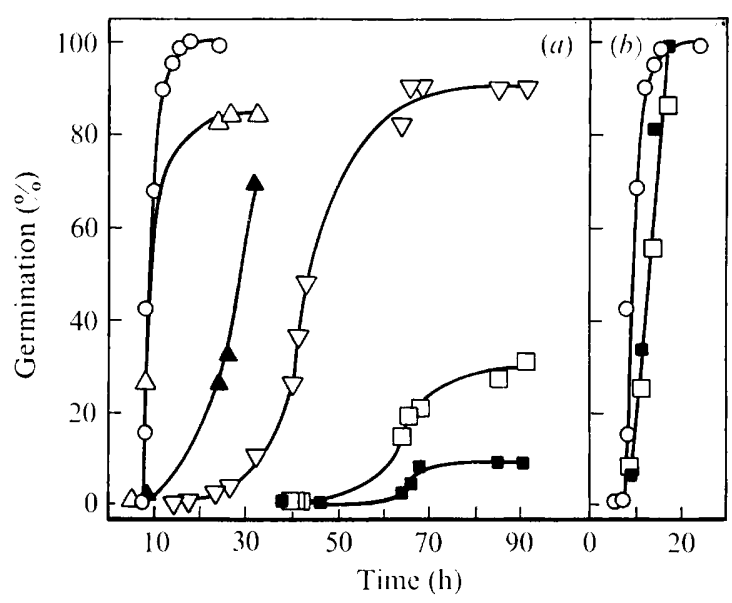

Fig. 2. Response of Cladosporium sp. to cycloheximide. (a) Percentage germination of unexposed conidia in the presence of cycloheximide at: $\triangle, 1.8 \mu \mathrm{M} ; \Delta, 18 \mu \mathrm{M} ; \nabla, 180 \mu \mathrm{M} ; \square, 1.8 \mathrm{mM} \square \mathbf{\square}$, $18 \mathrm{~mm}$; $\bigcirc$, control (no cycloheximide added). (b) Percentage germination of conidia exposed to $180 \mu \mathrm{M}$-cycloheximide on germination medium containing cycloheximide at: $\square, 1.8 \mathrm{~mm}$; $18 \mathrm{~mm} ; \bigcirc$, control (no cycloheximide added).

unexposed spores in medium containing $1.2 \mu \mathrm{M}$-cycloheximide when scored $6.5 \mathrm{~h}$ after inoculation (Table 2). Resistance to $12 \mu \mathrm{M}$-cycloheximide was acquired only after exposure to 1.2 or $12 \mu \mathrm{M}$-cycloheximide. However, this acquired resistance was lost when hyphae exposed to cycloheximide were sporulated in the absence of the drug. Mycelium grown in $12 \mu \mathrm{M}$-cycloheximide was completely inhibited at $120 \mu \mathrm{M}$.

\section{Cladosporium sp.}

When Cladosporium conidia from hyphae unexposed to cycloheximide were germinated on media containing up to $180 \mu \mathrm{M}$-cycloheximide, germination was inhibited by only $10 \%$, but there was a marked progressive increase in the lag from 8 to $44 \mathrm{~h}$ as measured by the time taken for $50 \%$ germination. Higher concentrations of cycloheximide caused progressively greater inhibition of total germination as well as further increases in the lag (up to $70 \mathrm{~h}$ ) (Fig. $2 a$ ). However, conidia derived from hyphae exposed to $180 \mu \mathrm{M}$-cycloheximide germinated completely after only a slight lag on media containing up to $18 \mathrm{~mm}$ cycloheximide (Fig. $2 b$ ). This resistance was lost after a single transfer in the absence of cycloheximide.

Cycloheximide caused a small decrease in the growth rate of hyphae. The specific growth rates $(\alpha)$ of unexposed hyphae were $0.0621 \mathrm{~h}^{-1}$ (S.E.M. $=0.0024$ ) and $0.0471 \mathrm{~h}^{-1}$ (S.E.M. $=$ 


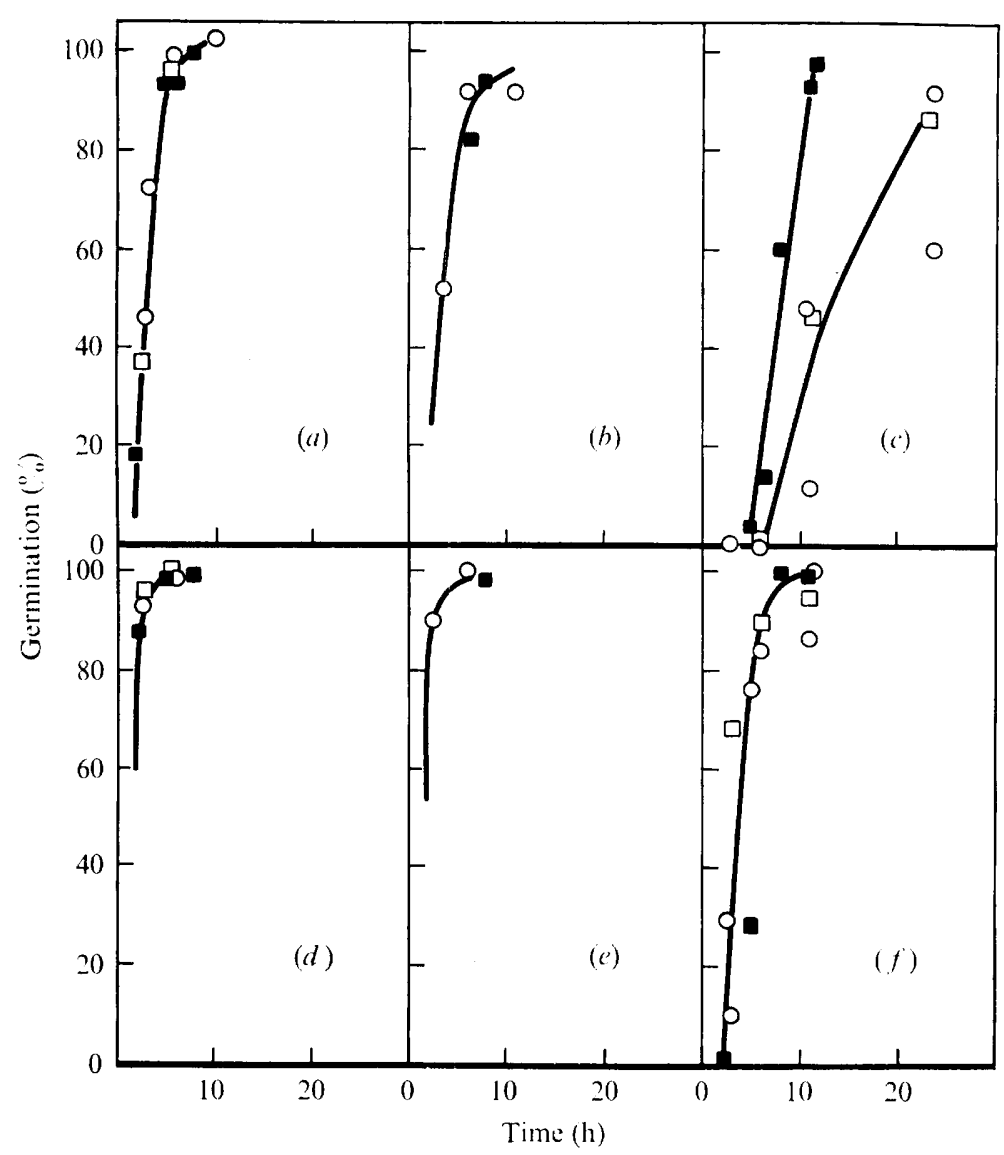

Fig. 3. Response of Microsporum gypseum $\mathrm{R} 87$ to cycloheximide at $37{ }^{\circ} \mathrm{C}(a, b, c)$ and $28^{\circ} \mathrm{C}$ $(d, e, f)$. Percentage germination in the presence of $1.8 \mathrm{~mm}(b, e)$ or $18 \mathrm{~mm}(c, f)$ cycloheximide in the germination medium, or in its absence $(a, d)$. Cycloheximide concentrations in the sporulation media were: $\bigcirc, 0 ; \square, 1.8 \mathrm{~mm} ; \mathbf{\square}, 18 \mathrm{~mm}$.

$0.0021)$ in the absence and presence of $18 \mathrm{~mm}$-cycloheximide respectively, while exposed hyphae gave corresponding values of $0.0508 \mathrm{~h}^{-1}$ (S.E.M. $\left.=0.0038\right)$ and $0.0449 \mathrm{~h}^{-1}$ (S.E.M. $=$ 0.0024 ). However, cycloheximide did cause a significantly longer lag with unexposed hyphal inocula. Lag phases (calculated as the time on the log dry weight growth line when the dry weight of the cultures equalled that of the inoculum) for unexposed hyphae were 11 and $32 \mathrm{~h}$ in the absence and presence of cycloheximide respectively, and those for exposed hyphae were 6 and $11 \mathrm{~h}$ respectively. These latter values are probably not significantly different from each other.

\section{Microsporum gypseum}

Macroconidia of $M$. gypseum derived from hyphae unexposed to cycloheximide were completely resistant, at both 28 and $37^{\circ} \mathrm{C}$, to antibiotic concentrations up to and including $1.8 \mathrm{~mm}$ (Fig. 3). Data are shown for strain R87 only; the other six strains produced similar results. Unlike Cladosporium, prior exposure of the macroconidia to the antibiotic did not significantly influence spore germination. When incubated at $28{ }^{\circ} \mathrm{C}$ on medium containing $18 \mathrm{~mm}$-cycloheximide, exposed and unexposed spores behaved similarly, but at $37^{\circ} \mathrm{C}$ germination of spores of strain $\mathrm{R} 87$ exposed to $18 \mathrm{~mm}$-cycloheximide was slightly delayed. Those exposed to $1.8 \mathrm{~mm}$ or unexposed showed a greater delay and decrease in the percentage germination. This pattern was not observed with the other strains used. 


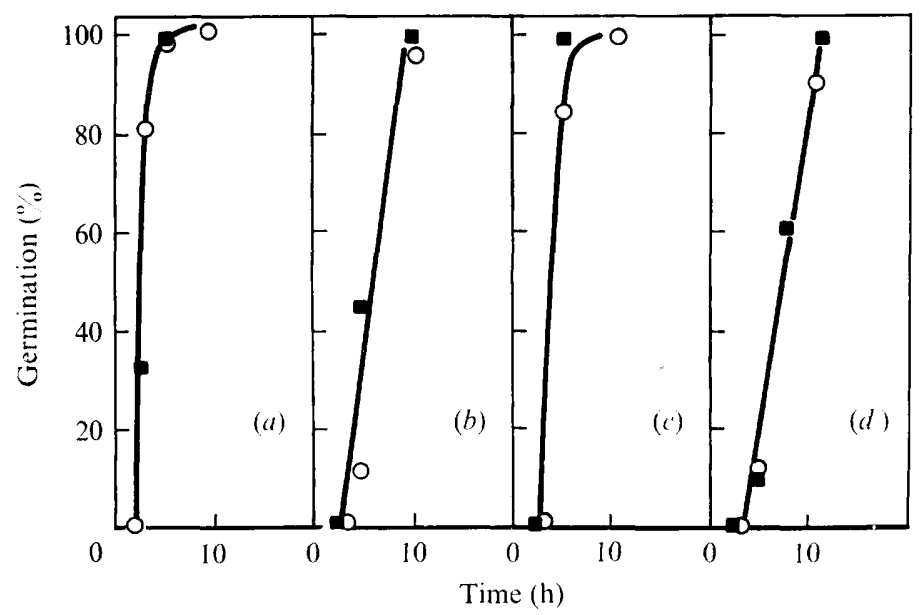

Fig. 4. Response of Trichophyton mentagrophytes 360A microconidia to cycloheximide at $37{ }^{\circ} \mathrm{C}$ $(a, b)$ and at $28^{\circ} \mathrm{C}(c, d)$. Percentage germination in the presence of 18 mm-cycloheximide in the germination medium $(b, d)$ or in its absence $(a, c)$. Cycloheximide concentrations in the sporulation media were: 0,$0 ; \mathbf{n}, 18 \mathrm{~mm}$.

\section{Trichophyton mentagrophytes}

Microconidia of $T$. mentagrophytes from hyphae unexposed to cycloheximide were completely resistant, at both 28 and $37^{\circ} \mathrm{C}$, to concentrations up to $18 \mathrm{~mm}$ (Fig. 4). Results obtained with strain 360A are shown; other strains behaved similarly. Prior exposure of microconidia to $18 \mathrm{~mm}$-cycloheximide did not alter these responses.

\section{DISCUSSION}

Two patterns of resistance to cycloheximide are apparent from our data. The first requires prior exposure to the antibiotic, suggesting an acquired resistance or adaptation, and is exhibited by the saprobes Achlya and Cladosporium. Achlya bisexualis showed acquired resistance by hyphal growth after a lag period in $12 \mu \mathrm{M}$-cycloheximide, by sporulation and germination of the resulting spores at $12 \mu \mathrm{M}$-cycloheximide and by the more rapid spore germination at $1.2 \mu \mathrm{M}$-cycloheximide after exposure to cycloheximide. Similarly, the complete resistance of exposed conidia of Cladosporium sp. and the decreased lag in the development of the hyphal fragments after exposure suggest an adaptation to cycloheximide. The mycelia of both genera acquire resistance more rapidly than spores. Only the mycelia of Achlya were able to acquire resistance in $12 \mu \mathrm{M}$-cycloheximide, although this resistance could be transferred to the spores produced. The unstable nature of the acquired resistance of spores or mycelia suggests that it was a transitory physiological phenomenon rather than a genetic process involving the induction or selection of mutants by exposure to cycloheximide.

The second pattern of resistance to cycloheximide, which appears to be constitutive rather than acquired, is demonstrated by the zoopathogens $M$. gypseum and T. mentagrophytes. The conidia and hyphae of all strains of both organisms exhibited an initial high resistance to cycloheximide which was unaltered by prior exposure to the drug.

The results obtained with $M$. gypseum strains, in particular R87, differ from those reported previously. Leighton \& Stock (1969) found that incubation at $37^{\circ} \mathrm{C}$ was required for maximum germination at $24 \mathrm{~h}$, with only poor germination at temperatures below $30^{\circ} \mathrm{C}$, but we found maximum germination at both 28 and $37^{\circ} \mathrm{C}$ within $24 \mathrm{~h}$. Dill, Leighton $\&$ Stock (1972) reported $100 \%$ inhibition of germination at $180 \mu \mathrm{M}$-cycloheximide $\left(50 \mu \mathrm{g} \mathrm{ml}^{-1}\right)$ while we found the antibiotic had no measurable effect upon germination at concentrations 
as high as $1.8 \mathrm{~mm}\left(500 \mu \mathrm{g} \mathrm{ml}^{-1}\right)$. We have no explanation for these differences. We have repeated our tests using their methods and obtained results identical to those presented here.

These studies show that scoring spore germination is an extremely useful system for assessing the responses of fungi to cycloheximide. It is more sensitive than measurement of hyphal growth as spores may be more susceptible. It is quicker than the colony diameter measurements utilized by Salkin (1975), and adaptation to cycloheximide is more readily detected than with longer term measurements such as maximum dry weights. While growthrate measurements by dry weight are accurate, they are also far more laborious and timeconsuming than spore germination measurements.

The authors wish to thank Dr Morris A. Gordon for his critical evaluation of the manuscript. The technical assistance of Ms Nancy Hurd is gratefully acknowledged. This work was supported in part by a grant from the Research Corporation, New York.

\section{REFERENCES}

Dill, B. C., Leighton, T. J. \& Stock, J. J. (1972). Physiological and biochemical changes associated with macroconidial germination in Microsporum gypseum. Applied Microbiology 24, 977-985.

Ford, J. H. \& LEACH, B. E. (1948). Actidione, an antibiotic from Streptomyces griseus. Journal of the American Chemical Society 70, 1223-1225.

Georg, L. K., Ajello, L. \& Gordon, M. A. (1951). A selective medium for the isolation of Coccidioides immitis. Science 114, 387-389.

Griffin, D. H. \& BreUKeR, C. (1969). Ribonucleic acid synthesis during the differentiation of sporangia in the water mold Achlya. Journal of Bacteriology 98, 689-696.

Griffin, D. H., Timberlake, W. E. \& Cheney, J. C. (1974). Regulation of macromolecular synthesis, colony development, and specific growth rate of Achlya bisexualis during balanced growth. Journal of General Microbiology 80, 381-388.

Grover, R. K. \& Moore, J. D. (1961). Adaptation of Sclerotinia fructicola and Sclerotinia laxa to higher concentrations of fungicides. Phytopathology 51, 399-401.

Gundersen, K. \& Wadstein, T. (1962). Morphological changes and resistance induced in Saccharomyces pastorianus by the antibiotic cycloheximide. Journal of General Microbiology 28, 325-332.

Leighton, T. J. \& Stock, J. J. (1969). Heat-induced macroconidia germination in Microsporum gypseum. Applied Microbiology 17, 473-475.
McDonough, E. S., Georg, L. K., Ajello, L. \& BrinkMAN, S. (1960). Growth of dimorphic human pathogenic fungi on media containing cycloheximide and chloramphenicol. Mycopathologia et mycologia applicata 13, 113-120.

Muler, I. \& Freund, J. E. (1965). Probability and Statistics for Engineers. Englewood Cliffs, New Jersey: Prentice-Hall.

SalkIN, I. F. (1975). Adaptation to cycloheximide: in vitro studies with filamentous fungi. Canadian Journal of Microbiology 21, 1413-1419.

Salkin, I. F. \& HuRd, N. (1972). Quantitative evaluation of the antifungal properties of cycloheximide. Antimicrobial Agents and Chemotherapy 1, 177-184.

TAPlin, D., Zaias, G. R. \& Blank, H. (1969). Isolation and recognition of dermatophytes on a new medium (DTM). Archives of Dermatology 99, 203-209.

TsaO, P. H. (1970). Selective media for isolation of pathogenic fungi. Annual Review of Phytopatho$\log y$ 8, 157-186.

WhIFFEN, A. J. (1948). The production, assay, and antibiotic activity of Actidione, an antibiotic from Streptomyces griseus. Journal of Bacteriology 56, 283-291.

WHIFFEN, A. J. (1950). The activity in vitro of cycloheximide (Acti-dione) against fungi pathogenic to plants. Mycologia 42, 253-258. 